\title{
The discriminative capacity of soluble Toll-like receptor (sTLR)2 and sTLR4 in inflammatory diseases
}

Jaap ten Oever ${ }^{1 *}$, Matthijs Kox ${ }^{2,3}$, Frank L van de Veerdonk ${ }^{1}$, Khutso M Mothapo ${ }^{1}$, Adriana Slavcovici ${ }^{4}$, Tim L Jansen ${ }^{5}$, Lieke Tweehuysen ${ }^{6}$, Evangelos J Giamarellos-Bourboulis ${ }^{7}$, Peter M Schneeberger ${ }^{8}$, Peter C Wever ${ }^{8}$, Monique Stoffels ${ }^{1}$, Anna Simon ${ }^{1}$, Jos WM van der Meer ${ }^{1}$, Melissa D Johnson ${ }^{9}$, Bart-Jan Kullberg ${ }^{1}$, Peter Pickkers ${ }^{2}$, Alexandre Pachot ${ }^{10}$, Leo AB Joosten ${ }^{1}$ and Mihai $G$ Netea $^{1}$

\begin{abstract}
Background: The extracellular domains of cytokine receptors are released during inflammation, but little is known about the shedding of Toll-like receptors (TLR) and whether they can be used as diagnostic biomarkers.

Methods: The release of sTLR2 and sTLR4 was studied in in-vitro stimulations, as well as in-vivo during experimental human endotoxemia ( $\mathrm{n}=11,2 \mathrm{ng} / \mathrm{kg}$ LPS), and in plasma of 394 patients with infections (infectious mononucleosis, measles, respiratory tract infections, bacterial sepsis and candidemia) or non-infectious inflammation (Crohn's disease, gout, rheumatoid arthritis, autoinflammatory syndromes and pancreatitis). Using C-statistics, the value of sTLR2 and sTLR4 levels for discrimination between infections and non-infectious inflammatory diseases, as well as between viral and bacterial infections was analyzed.
\end{abstract}

Results: In-vitro, peripheral blood mononuclear cells released sTLR2 and sTLR4 by exposure to microbial ligands. During experimental human endotoxemia, plasma concentrations peaked after 2 hours (sTLR4) and 4 hours (sTLR2). sTLR4 did not correlate with cytokines, but sTLR2 correlated positively with TNFa $\left(r_{s}=0.80, P<0.05\right)$, IL-6 $\left(r_{s}=0.65, P<0.05\right)$, and IL-1Ra $\left(r_{s}=0.57, P=0.06\right)$, and negatively with IL-10 $\left(r_{s}=-0.58, P=0.06\right)$, respectively. sTLR4 had a similar area under the ROC curve [AUC] for differentiating infectious and non-infectious inflammation compared to CRP: 0.72 ( $95 \% \mathrm{Cl} 0.66-0.79$ ) versus 0.74 (95\% Cl 0.69-0.80) $[\mathrm{P}=0.80]$, while sTLR2 had a lower AUC: 0.60 (95\% $\mathrm{Cl}$ 0.54-0.66) $[\mathrm{P}=0.0004]$. CRP differentiated bacterial infections better from viral infections than STLR2 and sTLR4: AUC 0.94 (95\% Cl 0.90-0.96) versus 0.58 (95\% Cl 0.51-0.64) and 0.75 (95\% Cl 0.70-0.80), respectively [P< 0.0001 for both].

Conclusions: sTLRs are released into the circulation, and suggest the possibility to use sTLRs as diagnostic tool in inflammatory conditions.

Keywords: Soluble Toll-like receptor, Biomarkers, Non-infectious inflammation, Experimental human endotoxemia

\section{Background}

Toll-like receptors (TLRs) are germline-encoded receptors that recognize microbial structures called pathogenassociated molecular patterns (PAMPs), either alone or in combination with co-receptors. Besides regulating innate and adaptive immune responses, TLR signaling plays an important role in the pathogenesis of several

\footnotetext{
* Correspondence: jaap.tenoever@radboudumc.nl

'Department of Internal Medicine (463), Radboud university medical center, P.O. Box 9101,6500 HB Nijmegen, The Netherlands

Full list of author information is available at the end of the article
}

inflammatory diseases, and tight regulation is crucial in order to prevent hyperinflammation $[1,2]$. Immune signaling is regulated at multiple levels, and the release of extracellular domains of immune receptors such as cytokine receptors represents an important regulatory mechanisms [3]. Similar negative regulation accounts for modulation of TLR function [1,2], and soluble forms of TLR2 and TLR4 have been recently described $[4,5]$. The release of these soluble proteins increases upon cell activation and they exert inhibitory activity on TLR signaling $[4,5]$. Soluble forms of TLRs have 
been detected in pleural fluid, amniotic fluid, saliva, breast milk and plasma [4,6-10].

Timely knowledge of the etiology of inflammatory conditions is crucial. Not only does it facilitate appropriate treatment, but also unnecessary interventions may be avoided. In light of the critical shortage of new antibiotics, reduction in antibiotic prescription is warranted.

The concept of measuring soluble pattern recognition receptors (PRRs) for the diagnosis of infections has been previously proposed for the TLR4-coreceptor CD14 $[11,12]$. However, analysis of soluble TLRs have up till now only been used in the diagnostic workup of pleural effusion and intra-amniotic infections [8-10,13].

The aim of the present study was to gain more insight into the release of sTLR2 and sTLR4 in-vitro and to investigate the kinetics of monocytic TLR2 and TLR4 expression and plasma levels of their soluble counterparts during experimental endotoxemia (intravenous LPS administration in healthy volunteers). Furthermore, we hypothesized that sTLR2 and sTLR4, being soluble forms of receptors that play pivotal roles in pathogen recognition by cells of the innate immune system, are differentially released during various inflammatory diseases, with higher levels in inflammatory conditions of infectious origin. As such, we evaluated the ability of sTLR2 and sTLR4 levels to discriminate between infectious and noninfectious inflammatory pathologies.

\section{Methods}

\section{In-vitro studies}

Peripheral blood mononuclear cells (PBMCs) were isolated from buffy coats of healthy individuals after informed consent. Briefly, PBMCs were isolated by density gradient centrifugation using Ficoll-Paque PLUS (GE Healthcare, Zeist, The Netherlands) and collecting the white interphase. Cells were washed twice in cold PBS and concentrations were adjusted to $5 \times 10^{6} \mathrm{cells} / \mathrm{ml}$ in RPMI-1640, supplemented $2 \mathrm{mML}$-glutamine, $1 \mathrm{mM}$ pyruvate and $50 \mu \mathrm{g} / \mathrm{ml}$ gentamicin (GIBCO Invitrogen, Carlsbad, CA). Mononuclear cells $\left(5 \times 10^{5}\right)$ in a $100-\mu \mathrm{l}$ volume were added to round-bottom 96-well plates (Greiner, Nurnberg, Germany) and incubated with either $100 \mu \mathrm{l}$ of culture medium (negative control), or LPS from E. coli O55:B5 (10 $\mu \mathrm{g} / \mathrm{ml}$; Sigma-Aldrich, St Louis, MO), Pam3Cys $(10 \mu \mathrm{g} / \mathrm{ml})$ or heat-killed E. coli ATCC 35218 $\left(10^{7} \mathrm{micro}\right.$-organisms $\left./ \mathrm{ml}\right)$. After 24 hour incubation at $37^{\circ} \mathrm{C}$, the supernatants were stored at $-80^{\circ} \mathrm{C}$ until measurement of sTLR2, sTLR4 and IL-6.

\section{Experimental human endotoxemia}

This study was part of a larger endotoxin trial registered at the ClinicalTrials.gov registry under the number NCT00783068 which was approved by the local ethics committee of the Radboud university medical center
[14]. The 11 healthy male volunteers included in the present study provided written informed consent. Briefly, subjects were prehydrated during $1 \mathrm{~h}$ before LPS administration by infusion of $1.5 \mathrm{~L} 2.5 \%$ glucose $/ 0.45 \%$ saline solution, followed by $150 \mathrm{ml} / \mathrm{h}$ starting at the time of LPS administration until $6 \mathrm{~h}$ afterwards and $75 \mathrm{ml} / \mathrm{h}$ until the end of the experiment. US Reference Escherichia coli endotoxin (LPS derived from E. coli O:113; Clinical Center Reference Endotoxin, National Institutes of Health, Bethesda, Md) was administered as an intravenous bolus $(2 \mathrm{ng} / \mathrm{kg})$. EDTA anticoagulated blood was collected from an arterial line.

\section{Flow cytometry for membrane TLR2 and TLR4 expression} In order to determine expression of TLR2 and TLR4, blood was collected in EDTA-containing vacutainers. The following directly conjugated mouse anti-human antibodies were used: TLR2: CD282 PE (mouse IgG2a, TLR 2.1 clone, eBioscience, San Diego, CA), TLR4: CD284 PECy7 (mouse IgG2a, HTA125 clone eBioscience, San Diego, CA), and CD14 ECD (mouse IgG2a, RMO52 clone Immunotech, Beckman Coulter, Marseille, France). Isotype and fluorochrome matched controls from Beckman Coulter were used. Cell buffer solution was used containing 0.5\% Bovine Serum Albumin in Phosphate Buffered Saline and $0.1 \%$ sodium azide. Rabbit serum (Invitrogen, Carlsbad, CA) for blocking was diluted to $20 \%$ with cell buffer solution. Red blood cell lysis was performed using $0.075 \mathrm{M}$ ammonium chloride $(\mathrm{NH} 4 \mathrm{Cl}, \mathrm{pH} 7.4)$, freshly prepared. $1 \mathrm{ml}$ of blood was mixed with $20 \mathrm{ml}$ of $\mathrm{NH} 4 \mathrm{Cl}$ lysing solution and was left at room temperature for 10 minutes. After centrifuging for 5 minutes at $500 \mathrm{~g}$ the supernatant was discarded. The cell pellet was resuspended in $50 \mathrm{ml}$ of PBS and centrifuged again. After this washing step the cell pellet was resuspended in $0.5 \mathrm{ml}$ cell buffer solution. $0.1 \mathrm{ml}$ of this cell suspension was mixed with $0.1 \mathrm{ml} 20 \%$ rabbit serum and left at room temperature for $10 \mathrm{~min}$. Subsequently, cells were incubated with the appropriate antibody concentration mixture for $15 \mathrm{~min}$ in the dark at room temperature. After washing, samples were resuspended in $0.5 \mathrm{ml}$ cell buffer solution and analyzed on a Beckman Coulter FC500 flow cytometer (Beckman Coulter, Miami, FL). Monocytes were gated in a Side Scatter vs. CD14 plot. Fluorochrome matched isotype controls, non-stained samples, as well as cells incubated with only a secondary antibody, were used to set the photo multiplier detectors. The TLR2 and TLR4 expression was analyzed within $\mathrm{CD} 14^{+}$monocytes.

\section{Biomarker study}

Plasma concentrations of sTLR2 and sTLR4 were measured in healthy controls, and two groups of patients and compared to that of the most used inflammatory biomarker, C-reactive protein (CRP). EDTA anticoagulated 
blood from the various groups of patients was prospectively collected during planned laboratory blood assessment for clinical purposes, or was available from previous clinical studies, as indicated. Plasma was obtained by centrifugation for 10 minutes at $2000 \mathrm{~g}$. The study has been carried out in the Netherlands in accordance with the applicable rules concerning the review of research ethics committees and informed consent. Inclusion and exclusion criteria for the inflammatory disorders are shown in Table 1 . Table 2 shows the demographic characteristics of the healthy controls and the patients included.

The first group consisted of patients with infectious diseases in whom plasma was obtained $\leq 24$ hours after presentation: viral lower respiratory tract infections (LRTI) ( $\mathrm{n}=25$; Table 3), measles [15] $(\mathrm{n}=43)$, infectious mononucleosis caused by either Epstein-Barr virus (EBV) [16] or cytomegalovirus (CMV) infection $(n=16)$, bacterial and viral respiratory co-infections $(n=20$; Table 3$)$, bacterial sepsis [17], stratified into sepsis, severe sepsis and septic shock [18] $(\mathrm{n}=156)$, and candidemia [19] $(\mathrm{n}=26)$. The second group comprised of patients with non-infectious inflammation: Crohn's disease $(n=15)$, gout $(\mathrm{n}=36)$, autoinflammatory syndromes $(\mathrm{n}=15)$, rheumatoid arthritis $(n=20)$, and pancreatitis [20] $(n=22)$. Patients with autoinflammatory syndromes consisted mainly of patients with well-known, genetically confirmed autoinflammatory diseases, like hyperimmunoglobulin-D syndrome, familial Mediterranean fever, Muckle-Wells syndrome and tumor necrosis factor receptor-1 associated syndrome (TRAPS). Pancreatitis was of biliary origin in $45 \%$, none developed necrosis and all had negative blood cultures. Samples were taken $\leq 24$ hours after presentation, except for Crohn's disease and reumatoid arthritis. Those were taken during an exacerbation of the disease (Table 1). The disease activity of rheumatoid arthritis was measured with Disease Activity Score (DAS) in 28 joints (DAS28) [21]. The definition of active rheumatoid arthritis is a DAS28 > 3.2. The mean DAS28 was 4.49 (range 3.40-6.40, of whom 7 patients had a score $>5.1$, indicating high disease activity).

Table 1 Description of included inflammatory disorders

\begin{tabular}{|c|c|c|}
\hline Inflammatory disorder & Inclusion criteria & Exclusion criteria \\
\hline \multirow[t]{3}{*}{ Crohn's disease } & Compatible endoscopic and histopathologic findings & - \\
\hline & Exacerbation & \\
\hline & Before first TNFa-antagonist infusion & \\
\hline \multirow[t]{2}{*}{ Rheumatoid arthritis } & Fulfilling the 2010 ACR RA and 1987 RA criteria & - \\
\hline & DAS28 $>3.2$ & \\
\hline \multirow[t]{2}{*}{ Gout } & Acute arthritis & - \\
\hline & Urate crystal positive or previously diagnosed gout & \\
\hline \multirow[t]{2}{*}{ Autoinflammatory syndrome } & Known history of autoinflammatory disorder & - \\
\hline & Typical attack & \\
\hline \multirow[t]{4}{*}{ Pancreatitis [20] } & Acute characteristic epigastric pain & HIV \\
\hline & SIRS [17] & Neutropenia $\left(<1000 / \mathrm{mm}^{3}\right)$ \\
\hline & Serum and urinary amylase levels $\geq 3 \times$ ULN & Chronic corticosteroid use \\
\hline & Compatible imaging (CT or ultrasound) findings & \\
\hline \multirow[t]{2}{*}{ Infectious mononucleosis [16] } & Compatible clinical signs & - \\
\hline & EBV (VCA) or CMV IgM positive & \\
\hline \multirow[t]{2}{*}{ Measles [15] } & Febrile rash & - \\
\hline & Measles IgM positive & \\
\hline \multirow[t]{2}{*}{ Viral respiratory tract infection } & Symptoms/signs of respiratory tract infection & Positive sputum or blood culture \\
\hline & Positive PCR from respiratory tract secretions & \\
\hline \multirow[t]{3}{*}{ Respiratory co-infections } & Symptoms/signs of respiratory tract infection & - \\
\hline & Positive PCR from respiratory tract secretions & \\
\hline & Positive sputum or blood culture & \\
\hline \multirow[t]{2}{*}{ Bacterial sepsis [17] } & International sepsis definition [17] & HIV \\
\hline & & Neutropenia $\left(<1000 / \mathrm{mm}^{3}\right)$ \\
\hline Candidemia [19] & Positive blood culture for Candida & - \\
\hline
\end{tabular}


Table 2 Demographic characteristics of the healthy controls and patients

\begin{tabular}{lccc}
\hline Group & Number & $\begin{array}{l}\text { Age } \\
\text { Years (IQR) }\end{array}$ & $\begin{array}{l}\text { Sex } \\
\text { \% male }\end{array}$ \\
\hline Healthy controls & 29 & $24(20-46)$ & 69 \\
Crohn's disease & 15 & $36(21-47)$ & 27 \\
Rheumatoid arthritis & 20 & $60(53-67)$ & 30 \\
Gout & 36 & $68(54-75)$ & 83 \\
Autoinflammatory syndrome & 15 & $32(22-42)$ & 29 \\
Pancreatitis & 19 & $64(58-72)$ & 80 \\
Infectious mononucleosis & 16 & $31(22-37)$ & 50 \\
Measles & 43 & $7(3-12)$ & 43 \\
Viral respiratory tract infection & 25 & $29(17-42)$ & 52 \\
Respiratory co-infections & 20 & $11(2-49)$ & 70 \\
Bacterial sepsis & 49 & $75(49-79)$ & 58 \\
Bacterial severe sepsis & 50 & $74(59-80)$ & 56 \\
Bacterial septic shock & 57 & $72(60-78)$ & 56 \\
Candidemia & 26 & $59(41-71)$ & 69 \\
\hline
\end{tabular}

Abbreviation: IQR interquartile range

\section{Cytokine and sTLR2 and sTLR4 measurement}

sTLR2 and sTLR4 concentrations were measured by a commercial ELISA kits (USCN Life Science, Inc., Wuhan, China) with a lower limit of detection of $0.312 \mathrm{ng} / \mathrm{ml}$ and $0.156 \mathrm{ng} / \mathrm{ml}$, respectively. A commercial ELISA (Sanquin, Amsterdam, The Netherlands) with a minimal detection level of $1.56 \mathrm{pg} / \mathrm{ml}$ was used for the determination of Interleukin (IL)-6 concentrations in supernatants. IL-6, tumor necrosis factor (TNF) $\alpha$, IL-1Ra and IL-10 concentrations in plasma were determined using a Luminex assay (Bio-plex cytokine assay, BioRad, Hercules, CA), with a sensitivity of $6 \mathrm{pg} / \mathrm{ml}, 20 \mathrm{pg} / \mathrm{ml}, 72 \mathrm{pg} / \mathrm{ml}$ and $6 \mathrm{pg} / \mathrm{ml}$, respectively. CRP concentrations were measured with a commercial ELISA, with a lower detection limit of $5 \mathrm{mg} / \mathrm{l}$ (IBL International, Hamburg, Germany). Samples were diluted when appropriate.

\section{Statistical analysis}

Cytokine and sTLR concentrations in the in-vitro and endotoxemia experiments are expressed as mean \pm SEM. For the assessment of correlations Spearman correlation coefficient was calculated. The Mann-Whitney $U$-test was used for the comparison of two groups in the biomarker study. Additionally, to correct for the potential influence of age and sex on the biomarker concentrations, we performed multiple linear regression analysis (forced entry method) with the biomarker of interest as dependent variable and age, sex and the assigned group (infection/no infection or bacterial/viral infection) as independent variable.
Table 3 Demographic and clinical characteristics of the patients with viral respiratory tract infections $(n=25)$ and bacterial respiratory tract super infections $(n=20)$

\begin{tabular}{|c|c|c|}
\hline Variable & Viral & Bacterial \\
\hline Male/Female (\% male) & $13 / 12(52)$ & $14 / 6(70)$ \\
\hline Age, yrs [median (IQR)] & $29(17-42)$ & $11(2-49)$ \\
\hline Admission to the hospital ward, no (\%) & $14(56)$ & $20(100)$ \\
\hline ICU admission, no (\%) & $1(4)$ & $13(65)$ \\
\hline \multicolumn{3}{|l|}{ Comorbidities } \\
\hline None, no (\%) & $9(36)$ & $6(30)$ \\
\hline Diabetes mellitus, no (\%) & $1(4)$ & $0(0)$ \\
\hline $\begin{array}{l}\text { Chronic obstructive pulmonary disorder or } \\
\text { asthma, no (\%) }\end{array}$ & $7(28)$ & $3(15)$ \\
\hline Chronic renal disease, no (\%) & $1(4)$ & $2(10)$ \\
\hline Solid or hematological malignancy, no (\%) & $6(24)$ & $6(30)$ \\
\hline Cardiovascular disease, no (\%) & $3(12)$ & $2(10)$ \\
\hline Other, no (\%) & $5(20)$ & $6(30)$ \\
\hline \multicolumn{3}{|l|}{ Viral pathogen } \\
\hline Influenza virus, no (\%) & $17(68)$ & $7(35)$ \\
\hline Respiratory syncythial virus, no (\%) & $0(0)$ & $6(30)$ \\
\hline Parainfluenza virus, no (\%) & $3(12)$ & $5(25)$ \\
\hline Coronavirus, no (\%) & $2(8)$ & $0(0)$ \\
\hline Human metapneumovirus, no (\%) & $1(4)$ & $0(0)$ \\
\hline Adenovirus, no (\%) & $0(0)$ & $2(10)$ \\
\hline Parecho-/rhinovirus, no (\%) & $1(4)$ & $0(0)$ \\
\hline Respiratory syncythial/rhinovirus, no (\%) & $1(4)$ & $0(0)$ \\
\hline \multicolumn{3}{|l|}{ Bacterial pathogen } \\
\hline S. aureus, no (\%) & $0(0)$ & $5(25)$ \\
\hline S. pneumonia, no (\%) & $0(0)$ & $3(15)$ \\
\hline P. aeruginosa, no (\%) & $0(0)$ & $4(20)$ \\
\hline S. pneumoniae/H. influenzae, no (\%) & $0(0)$ & $2(10)$ \\
\hline S. pneumonia/M. catarrhalis, no (\%) & $0(0)$ & $1(5)$ \\
\hline Other (combinations), no (\%) & $0(0)$ & $5(25)$ \\
\hline 28-day mortality, no (\%) & $1(4)$ & $3(15)$ \\
\hline
\end{tabular}

Abbreviations: IQR interquartile range, ICU intensive care unit.

Receiver operating characteristics (ROC) curve statistics were applied to calculate sensitivity and specificity. In order to determine the diagnostic accuracy of the combination of biomarkers, logistic regression analysis was used to estimate the predicted probabilities, which were subsequently used for the generation of a ROC curve. The method described by DeLong was used for comparing areas under ROC curves (AUC) [22]. All tests were two-sided, and $\mathrm{P}<0.05$ was considered statistically significant. Data were analyzed using Graph Pad Prism 5 (GraphPad Software, La Jolla, CA) and MedCalc version 11.3.1.0 (MedCalc Software, Mariakerke, Belgium). 


\section{Results}

In-vitro release of soluble TLRs by human PBMCs

sTLR2 and sTLR4 were below the detection limit (6 and $8 \mathrm{ng} / \mathrm{ml}$, respectively) in the supernatants of unstimulated PBMCs. After stimulation with LPS, Pam3Cys or heat-killed E. coli, significant amounts of IL-6, sTLR2 and sTLR4 were released by PBMCs in the supernatant, although shedding of sTLRs was not confined to stimulation of its corresponding cell surface receptor (Figure 1).

\section{sTLR2 and sTLR4 release during human endotoxemia}

sTLR2 and sTLR4 plasma concentrations displayed a distinct pattern after LPS infusion (Figure 2). Before LPS administration, sTLR2 and sTLR4 levels were undetectable or low in all volunteers. sTLR4, TNF $\alpha$, IL-6 and IL-10 concentrations increased after LPS infusion and reached a peak concentration at 2 hours LPS infusion; sTLR2 and IL-1Ra peaked after 4 hours. The mean peak values $( \pm$ SEM) were $357 \pm 94 \mathrm{ng} / \mathrm{ml}$ for sTLR2, $10.5 \pm$ $2.3 \mathrm{ng} / \mathrm{ml}$ for sTLR4, $836 \pm 288 \mathrm{pg} / \mathrm{ml}$ for TNF $\alpha, 926 \pm$ $145 \mathrm{pg} / \mathrm{ml}$ for IL-6, $90 \pm 17 \mathrm{pg} / \mathrm{ml}$ for IL-10, and $26081 \pm 2213 \mathrm{pg} / \mathrm{ml}$ for IL-1Ra, respectively. The AUC of sTLR4 showed no correlation with the AUCs of sTLR2 $\left(r_{\mathrm{s}}\right.$ 0.03, $\left.\mathrm{P}=0.94\right)$, IL-6 $\left(\mathrm{r}_{\mathrm{s}}-0.07, \mathrm{P}=0.83\right)$, TNF $\alpha\left(\mathrm{r}_{\mathrm{s}}-0.07\right.$, $\mathrm{P}=0.80), \quad \mathrm{IL}-10\left(\mathrm{r}_{\mathrm{s}} 0.22, \mathrm{P}=0.52\right)$, and $\mathrm{IL}-1 \mathrm{Ra}\left(\mathrm{r}_{\mathrm{s}} 0.14\right.$, $\mathrm{P}=0.69)$. However, sTLR2 showed a strong positive correlation with TNF $\alpha\left(r_{s} 0.80, P=0.003\right)$, IL-6 $\left(r_{s} 0.65, P=0.03\right)$. sTLR2 showed a trend towards a positive correlation with IL-1Ra $\left(\mathrm{r}_{\mathrm{s}} 0.57, \mathrm{P}=0.06\right)$, and a negative with IL-10 $\left(r_{\mathrm{s}}-0.58, \mathrm{P}=0.06\right)$, respectively.

Cell-surface expression of TLR2 and TLR4 on monocytes varied extensively among the subjects without a clear pattern and did not correlate with sTLR2 and sTLR4 plasma levels (Figure 2).

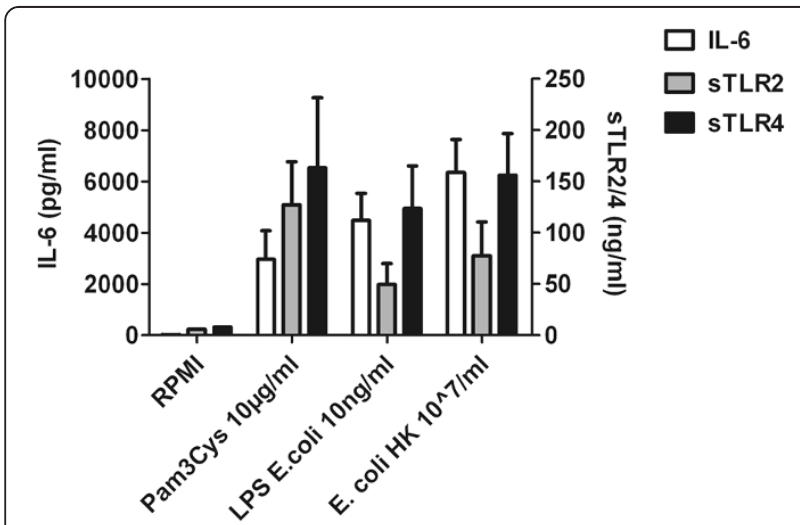

Figure 1 Release of IL-6, sTLR2 and sTLR4 after stimulation for 24 hours of peripheral blood mononuclear cells with either medium (control) several microbial stimuli. Data are expressed as means \pm SEM $(n=6)$. The concentrations of IL-6, sTLR2 and sTLR4 after incubation with medium are below the detection limit.

\section{Circulating concentrations of sTLR2 and sTLR4 in various inflammatory diseases}

Figure 3 shows the circulating concentrations of CRP, sTLR2 and sTLR4 in various infectious and non-infections inflammatory diseases. 394 patients and 29 healthy volunteers were included. For determination of CRP, samples of 351 patients and 11 healthy volunteers were analyzed. CRP, sTLR2 and sTLR4 circulating concentrations were significantly higher in patients with infection compared with patients with non-infectious inflammation (Figure 4, groups $\mathrm{A}$ and $\mathrm{B}$ ). After correction for age and sex, the presence of an infection was still positively associated with CRP, sTLR2 and sTLR4: unstandardized coefficients 85 (95\% CI 64-106, P<0.001), 23 (95\% CI 12-34, P < 0.001), and 6.2 (95\% CI 4.2-8.2, $\mathrm{P}<0.001$ ), respectively. Age, but not sex, was also positively associated with the three biomarker concentrations. Furthermore, compared with patients suffering from viral infections, patients with bacterial infections displayed higher concentrations of CRP and sTLR4, but not sTLR2 (Figure 4, groups C and D). Multivariate analysis with correction for age and sex showed all three biomarkers to be independently associated with the presence of a bacterial infection. Unstandardized coefficients for CRP, sTLR2 and sTLR4 were 113 (95\% CI 79-147, P<0.001), 19 (95\% CI 0.2-39, P = 0.04) and 6.2 (95\% CI 2.2-9.0, P =0.01), respectively. Neither sex, nor age proved to influence the concentrations of CRP, sLTR2 and sTLR4.

In the patients with bacterial or fungal sepsis, the presence of a malignancy $(n=27$; without malignancy $n=155)$ was associated with higher concentrations of CRP (152 vs $127 \mathrm{mg} / \mathrm{l}, \mathrm{P}=0.07$ ), sTLR2 (62 vs $23 \mathrm{ng} / \mathrm{ml}, \mathrm{P}=0.001$ ) and sTLR4 (7.2 vs $4.3 \mathrm{ng} / \mathrm{ml}, \mathrm{P}=0.15)$, although this only reached statistical significance for STLR2.

The discriminative value of sTLR4 levels to identify infectious versus non-infectious inflammation was similar compared with CRP: AUC of 0.72 (95\% CI 0.66-0.79) and 0.74 (95-\% CI 0.69-0.80), P = 0.80 (Table 4, Figure 5). sTLR2 performed worse: AUC 0.60 (95\% CI 0.54-0.66), $\mathrm{P}=0.0004$ compared to the AUC of CRP. At a specificity of $95 \%$, circulating concentrations of sTLR2 above $47 \mathrm{ng} / \mathrm{ml}$, sTLR4 above $18.9 \mathrm{ng} / \mathrm{ml}$, and CRP above $150 \mathrm{mg} / \mathrm{l}$ had a sensitivity of $32 \%, 16 \%$ and $28 \%$, respectively, to identify an infectious process. Combination of biomarkers showed no improvement of the AUC (Table 4).

CRP levels showed good value to discriminate between bacterial and viral infections with an AUC of 0.94 (95\% CI 0.90-0.96). sTLR4 levels displayed a significantly lower AUC compared with CRP: 0.75 (95\% CI 0.70-0.82), $\mathrm{P}<0.0001$. sTLR2 was a poor discriminator between patients with a bacterial or viral infection (Table 4, Figure 5). Panel analysis with two biomarkers was comparable to the performance of CRP alone. The cut-off values for the 


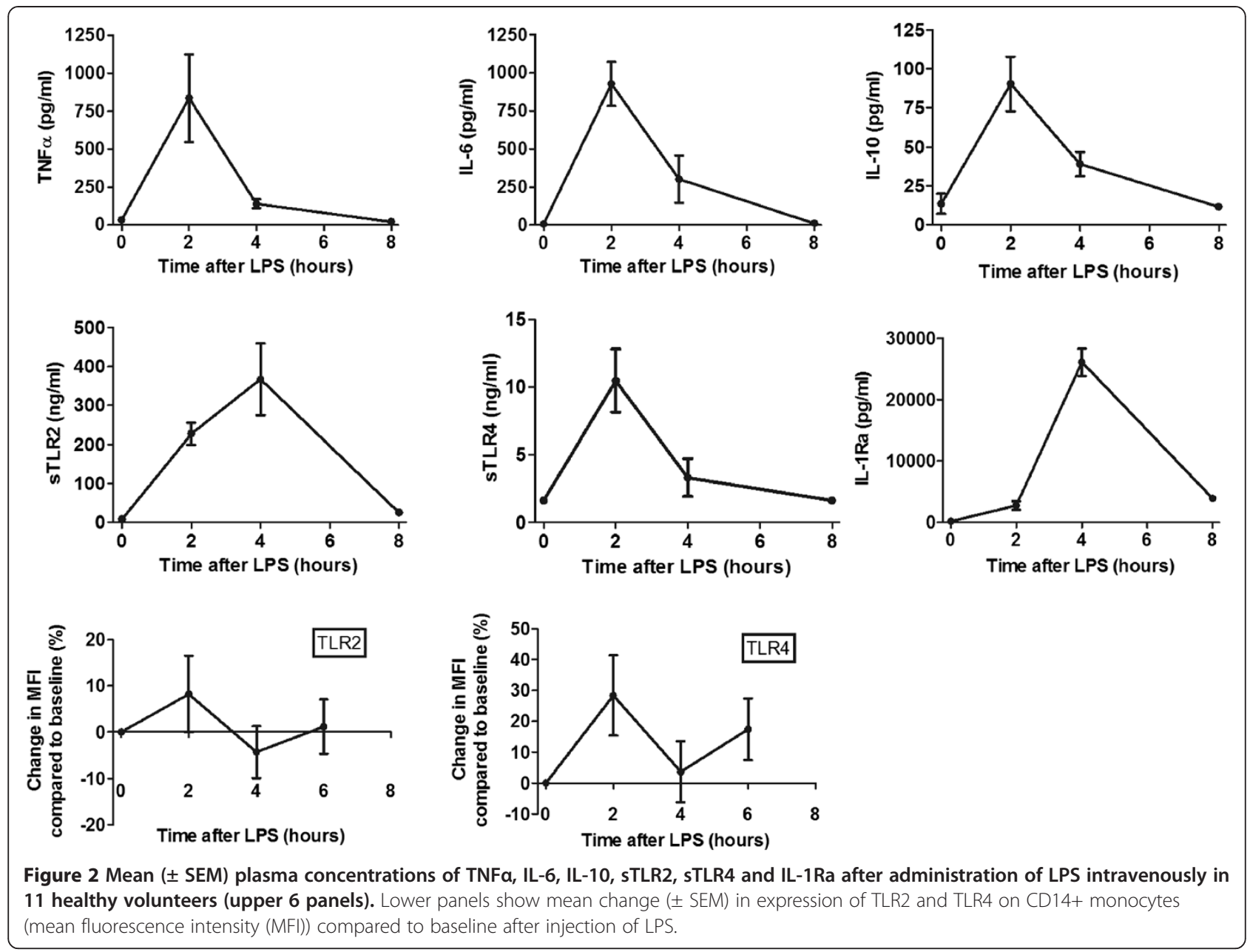

discrimination of bacterial infections from viral infections with a specificity of 95\% were for CRP $67 \mathrm{mg} / \mathrm{l}$ (sensitivity $82 \%$ ), for sTLR2 $79 \mathrm{ng} / \mathrm{ml}$ (sensitivity 23\%) and for sTLR4 $10.6 \mathrm{ng} / \mathrm{ml}$ (sensitivity $28 \%$ ).

\section{Discussion}

In the present study, we demonstrate that sTLR2 and sTLR4 are released in-vitro and in-vivo after challenge with microbial ligands such as LPS. Significantly elevated plasma concentrations of sTLRs are present in the circulation during experimental human endotoxemia, and high circulating concentrations of sTLR4 are found in patients with infections compared to patients with non-infectious inflammation, as well as in patients with bacterial infections compared with viral infections. However, the value of sTLR2 and sTLR4 as additional diagnostic biomarkers is low as both new markers do not surpass CRP in accuracy.

In addition to the release of sTLR2 and sTLR4 from stimulated immune cells $[4,5]$, constitutive release of sTLRs has been demonstrated in various biological fluids such as saliva, breast milk, and amniotic fluid $[10,23]$. In plasma, sTLR2 represented by several polypeptides, has been found by others [4], although the concentrations are low. To avoid both harmful or insufficient inflammatory responses, inhibition and activation of the immune system needs to be properly balanced. Various negative regulators of TLRs have been described [1] of which sTLR2 and sTLR4 constitute an important first-line negative regulatory mechanism [4-6,23-25]. sTLR2 either interferes with CD14-mediated triggering of membranebound TLR2, dimerizes with TLR2 on the cell surface, or competes with cellular TLR2 for microbial ligands [4]. The complex formed by sTLR4 and MD-2 probably blocks the interaction between membrane-bound TLR4 and its ligand [25]. The rapid elevation of sTLR2 and sTLR4 in plasma upon LPS administrations, similar to that of pro-inflammatory cytokines, indicates that this feedback mechanism is rapidly activated. Consistent with our in-vitro data, the release of sTLRs in to the circulation demonstrates that immune modulation mediated by TLRs is not limited to the stimulation of the corresponding receptor on the cell membrane of immune cells. Since both sTLR2 2 and sTLR4 dampen inflammation by disrupting 


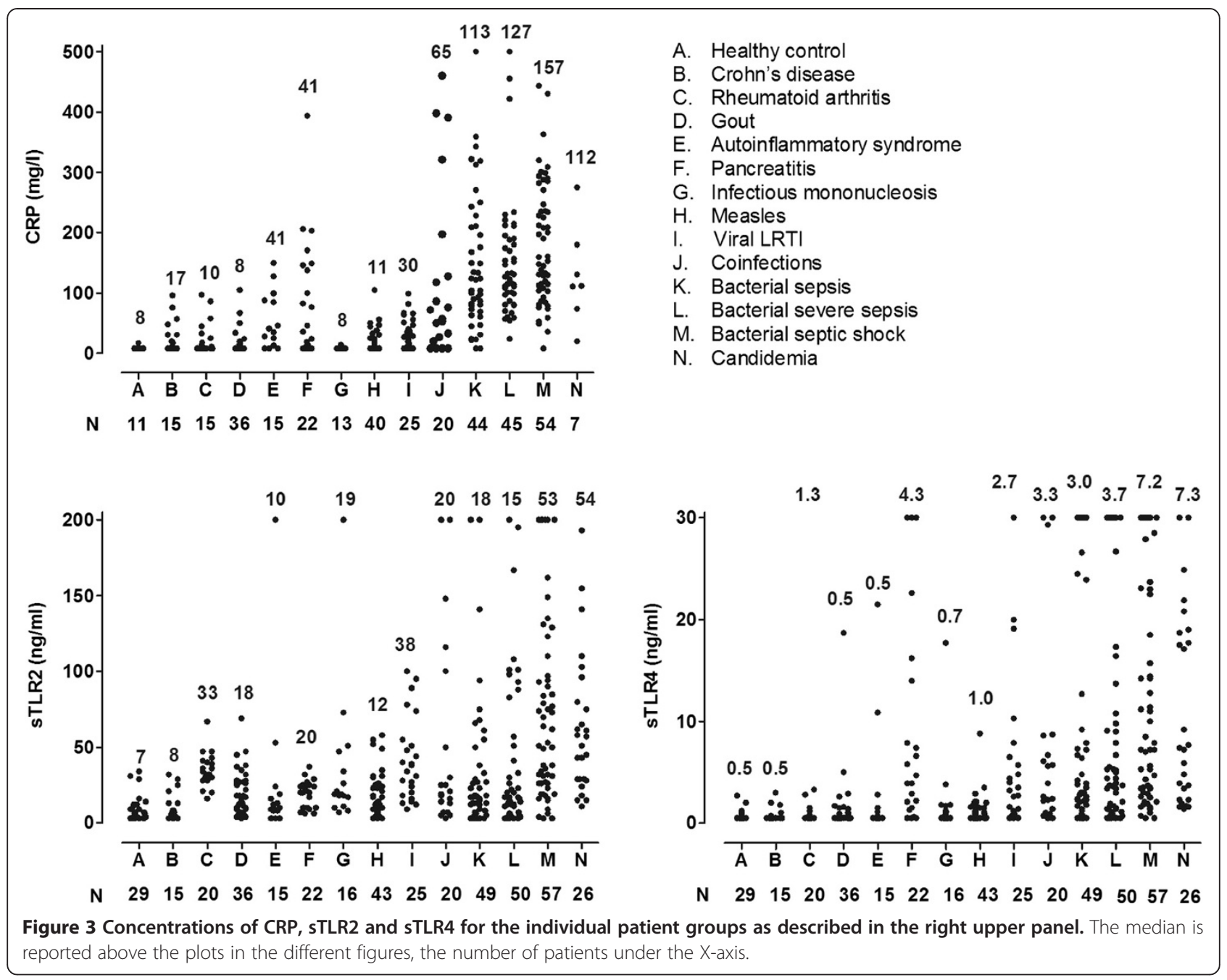

TLR-mediated pro-inflammatory responses [4-6,23-25], it might be possible that the counter regulatory mechanisms mediated by sTLRs extend to interference with endogenous TLR ligands. Although the kinetics of sTLR2 and sTLR4 concentrations parallel those of anti-inflammatory cytokines, quantitatively they appear to be differentially regulated. Plasma sTLR4 levels did not show any correlation with both IL-10 and IL-1Ra and for sTLR2, a negative correlation with IL-10 was found. Interestingly, while in-vitro release of sTLR2 and sTLR4 by immune cells is comparable, their in-vivo concentrations differ strongly, with much higher concentration in the circulation of sTLR2: this suggests a much more rapid clearance of sTLR4 from circulation. This may imply that these anti-inflammatory mechanisms are regulated at a different level and are potential complementary strategies to reduce inflammation.

In recent years, an important role for TLR signaling has been discovered in oncogenesis, particularly in inflammation-driven tumors [26]. Although the relationship between cell-bound TLR2 and its release as a soluble form is not clear-cut, the observed higher concentrations of sTLR2 in the (small) group of patients with an underlying malignancy may reflect the increased expression of TLR2 as seen in some forms of cancer [26].

Alternatively spliced TLR4 mRNA encodes the soluble form of TLR4 [5]. As such, we did not expect a correlation between the membrane expression of TLR4 and circulating sTLR4. On the contrary, sTLR2 results from posttranslational processing: endocytosis of cell surface receptor is followed by conversion into sTLR2 intracellularly [4]. In previous monocyte stimulation experiments, membrane-bound TLR2 correlated negatively with supernatant sTLR2 [4]. We did not observe the downregulation of cell surface TLR expression on monocytes of individuals during endotoxemia. Possible explanations for this lack of correlation are that (1) monocytes are detected only in very low numbers at 2 hours after LPS injection [27] and this subpopulation may well have a different TLR expression than more active monocytes that have 


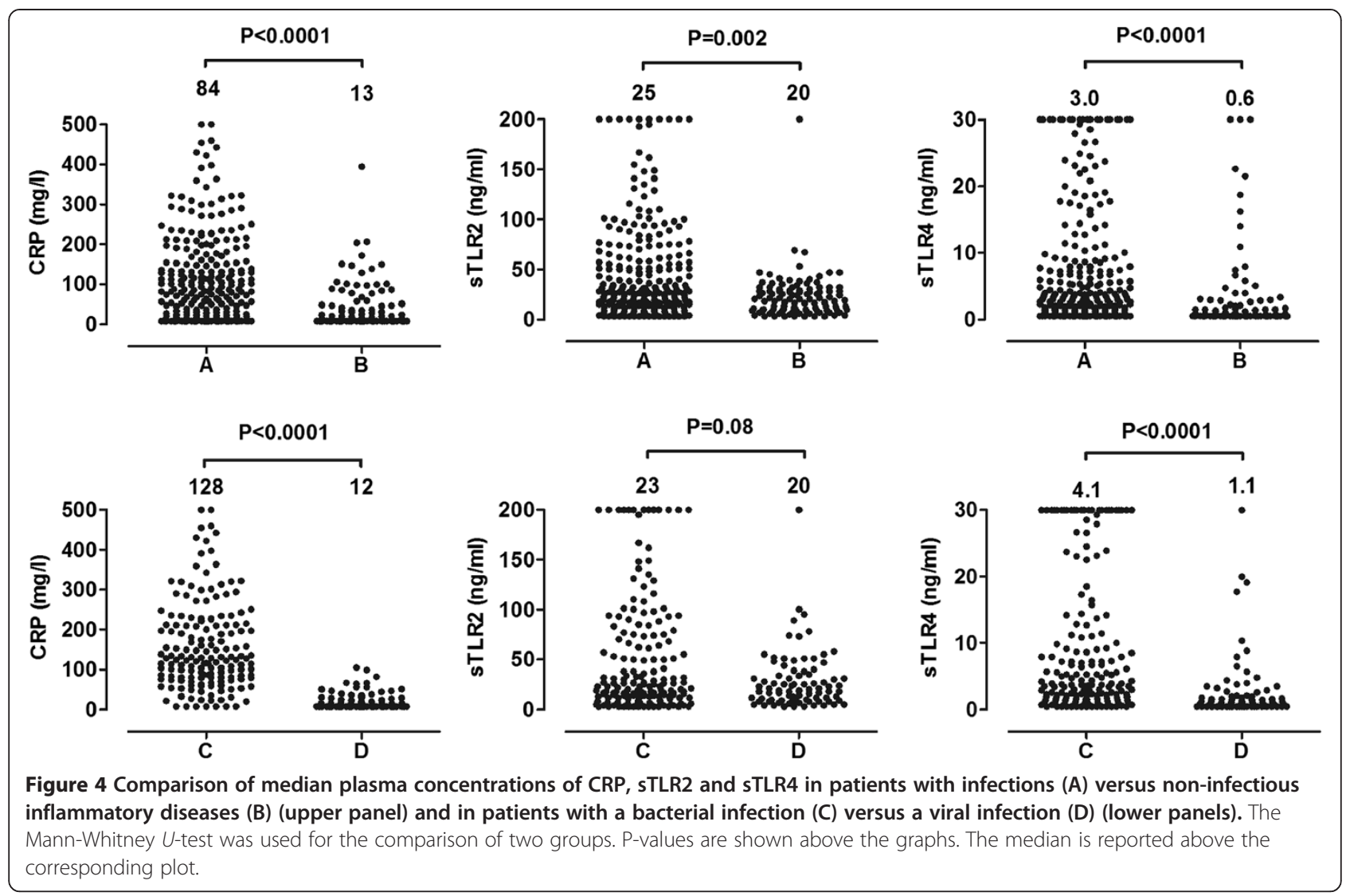

marginated at this time-point; (2) we only examined the expression of TLRs on monocytes $\left(\mathrm{CD} 14^{+}\right)$, however, other circulating cell subsets such as neutrophils or platelets also express TLR2 $[28,29]$, all potentially contributing to the plasma concentrations of sTLRs; (3) the soluble receptors are derived from an intracellular pool, not directly from the cell surface [4]; and finally (4) besides being shed, membrane bound TLR is influenced by TLR trafficking between intracellular compartments and the cell membrane [30].

An important aspect of this study is the possibility to use soluble TLRs as diagnostic markers. Rapid and reliable differentiation of non-infectious inflammatory disorders from infections, and the classification of infections according to their microbiological etiology is essential for optimal treatment of these conditions. So far, only a small number of studies have been published on sTLRs as diagnostic biomarkers. A few studies from the same group reported that intrauterine infections in pregnant women are characterized by elevated levels of sTLR1, sTLR2, sTLR6 and sTLR4 in the amniotic fluid $[9,10,13]$, supporting the concept of sTLR release during infections. We assessed the value of sTLR2 and sTLR4 levels to discriminate between several inflammatory

Table 4 AUC of the ROC for the discrimination between an infection and non-infectious inflammation and between bacterial and viral infection

\begin{tabular}{|c|c|c|c|c|}
\hline Biomarker & $\begin{array}{l}\text { Infection vs no infection } \\
\text { AUC }(95 \% \mathrm{Cl})\end{array}$ & P-value & $\begin{array}{l}\text { Bacterial infection vs viral infection } \\
\text { AUC }(95 \% \mathrm{Cl})\end{array}$ & P-value \\
\hline CRP & $0.74(0.69-0.80)$ & - & $0.94(0.90-0.96)$ & - \\
\hline sTLR2 & $0.60(0.54-0.66)$ & 0.0004 & $0.58(0.51-0.64)$ & $<0.0001$ \\
\hline sTLR4 & $0.72(0.66-0.79)$ & 0.80 & $0.75(0.70-0.80)$ & $<0.0001$ \\
\hline sTLR2 + sTLR4 & $0.65(0.60-0.70)$ & 0.01 & $0.75(0.69-0.80)$ & $<0.0001$ \\
\hline sTLR2 + CRP & $0.75(0.70-0.80)$ & 0.66 & $0.94(0.90-0.96)$ & 0.36 \\
\hline sTLR4 + CRP & $0.76(0.71-0.80)$ & 0.25 & $0.95(0.91-0.97)$ & 0.13 \\
\hline
\end{tabular}

Shown P-value for the comparisons of the AUCs with the AUC of CRP.

Abbreviations: AUC area under the curve; $\mathrm{Cl}$ confidence interval. 

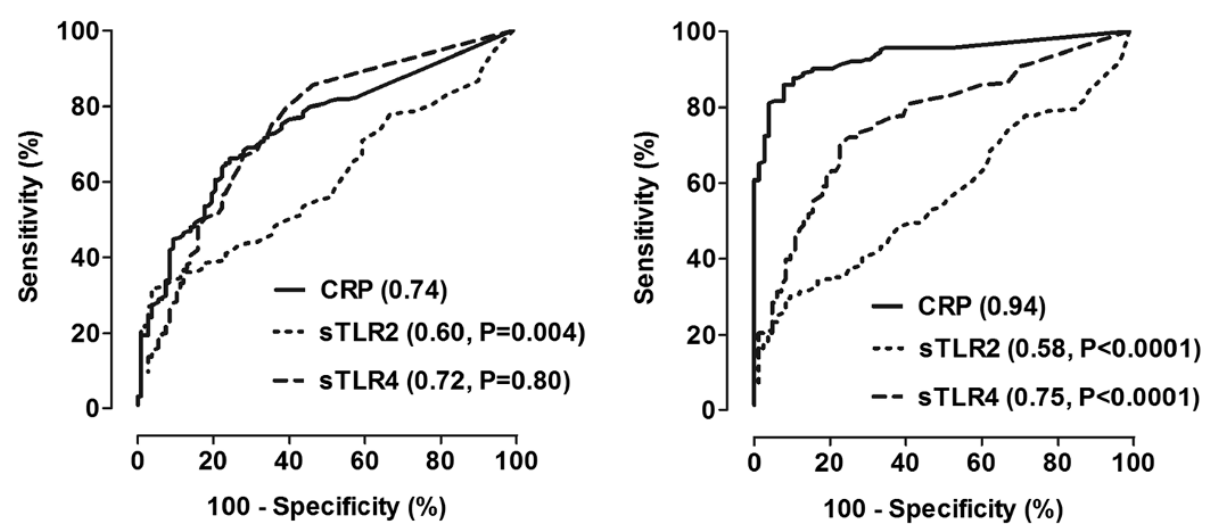

Figure 5 ROC curves of CRP, sTLR2 and sTLR4 for the comparison between patients with infections and non-infectious inflammation (left panel) and between patients with a bacterial and viral infection (right panel). AUCs are shown between brackets. P-values indicate the comparison of the AUC of sTLR2, sTLR4 and CRP.

conditions. sTLR2 and sTLR4 were elevated in response to inflammatory insults and particularly sTLR4 showed a good specificity to discriminate between an infection and a non-infectious inflammatory conditions such as gout, Crohn's disease, rheumatoid arthritis or autoinflammatory syndromes. Moreover, sTLR4 concentrations show a high specificity for discriminating between bacterial and viral infections using high cut-off values, but sensitivity was low. We have to mention however that the overall discriminative value of sTLR levels was not superior to that of CRP in the relatively small group of patients assessed in this study Future larger validation studies should demonstrate the overall value of sTLR2 and sTLR4 levels for the diagnosis of infections and autoinflammatory diseases in relation to that of classic inflammatory markers. Furthermore, besides sTLRs, other soluble pattern recognition receptors such as the soluble mannose receptor that are shed during cell stimulation with $\beta$-glucans are also interesting candidates for new and potentially more specific diagnostic biomarkers [31].

Our study also has limitations. Firstly, it included a relatively limited number of clinical conditions, and it is not possible to extrapolate our results to the entire panel of infectious or non-infectious inflammatory diseases. Secondly, we studied groups of inflammatory conditions as a whole, rather than focusing on correlation with other clinical information or outcome.

\section{Conclusions}

The present study is an important initial proof-ofprinciple report on the role of sTLR2 and sTLR4 during a broad panel of human infections and autoinflammatory diseases. Shedding of sTLR2 and sTLR4 is not confined to stimulation of its corresponding cell surface receptor, but it is a broader effect upon stimulation of innate immune cells through pattern recognition receptors. We report the significant increase of sTLR2 and sTLR4 both in experimental models of human endotoxemia, as well as in the circulation of patients with infections. This suggests an important role of soluble TLRs in the modulation of inflammation during infections and the potential to use these tests as diagnostic markers. Therefore, larger validation studies in larger patient cohorts are warranted in order to be able to draw definitive conclusions regarding the diagnostic usefulness of sTLR2 and sTLR4 in human inflammatory diseases.

\section{Abbreviations \\ ACR: American College of Rheumatology; AUC: Area under the ROC curve; Cl: Confidence interval; CMV: Cytomegalovirus; CRP: C-reactive protein; DAS: Disease Activity Score; EBV: Epstein-Barr virus; IQR: Interquartile range; ICU: Intensive care unit; IL: Interleukin; MFI: Mean fluorescence intensity; PRR: Pathogen recognition receptor; PAMP: Pathogen-associated molecular patterns; PBMC: Peripheral blood mononuclear blood cells; ROC: Receiver operating characteristics; SEM: Standard error of the mean; sTLR: Soluble Toll-like receptor; TNF: Tumor necrosis factor; TRAPS: Tumor necrosis factor receptor-1 associated syndrome; ULN: Upper limit of normal; CVA: Viral capsid antigen.}

\section{Competing interests}

The authors declare that they have no competing interests.

\section{Authors' contributions}

JtO: included patients for the biomarker study, performed the ELISAs, performed the statistical analysis and drafted the first manuscript. MK and PP: performed the human endotoxemia study. KM: performed the in-vitro experiments and the ELISAs. FvdV, AS, AS, MS, MJ, TLJ, LT, PS, PMW, PCW: included patients for the biomarker study. JWM, B-JK, AP: contributed to conception and design of the study. LABJ and MGN contributed to the conception and design of the study and the analysis and interpretation of the data. All the authors revised the manuscript critically for important intellectual content and approved the final version before submission.

\section{Acknowledgment}

We gratefully acknowledge Foekje Stelma for the collection of patient samples.

This work was partly supported by an unrestricted research grant of Institut Mérieux. J.t.O. was supported by European Regional Development Fund province of Gelderland project [grant number 2009-010034]. M.G.N. was supported by a European Research Council Consolidator Grant [grant number 310372]. 


\section{Author details}

${ }^{1}$ Department of Internal Medicine (463), Radboud university medical center, P.O. Box 9101, 6500 HB Nijmegen, The Netherlands. ${ }^{2}$ Department of Intensive Care Medicine, Radboud university medical center, Nijmegen, The Netherlands. ${ }^{3}$ Department of Anaesthesiology, Radboud university medical center, Nijmegen, The Netherlands. ${ }^{4}$ Department of Infectious Diseases, 'Iuliu Hatieganu' Faculty of Medicine and Pharmacy, Cluj-Napoca, Romania. ${ }^{5}$ Department of Rheumatology, Radboud university nijmegen medical center, Nijmegen, The Netherlands. ${ }^{6}$ Department of Rheumatology, Sint Maartenskliniek, The Netherlands. ${ }^{7} 4$ th Department of Internal Medicine, University of Athens, Medical School, Athens, Greece. ${ }^{8}$ Department of Medical Microbiology and Infection Control, Jeroen Bosch Hospital, 's-Hertogenbosch, The Netherlands. ${ }^{9}$ Duke University Medical Center, Durham, NC, USA. ${ }^{10}$ Joint Unit " Sepsis » Hospices Civils de Lyon-bioMérieux, Hôpital Edouard Herriot, Lyon, France.

Received: 13 February 2014 Accepted: 4 November 2014 Published online: 19 November 2014

\section{References}

1. Liew FY, Xu D, Brint EK, O'Neill LA: Negative regulation of toll-like receptor-mediated immune responses. Nat Rev Immunol 2005, 5:446-458.

2. Cook DN, Pisetsky DS, Schwartz DA: Toll-like receptors in the pathogenesis of human disease. Nat Immunol 2004, 5:975-979.

3. Heaney ML, Golde DW: Soluble cytokine receptors. Blood 1996, 87:847-857.

4. LeBouder E, Rey-Nores JE, Rushmere NK, Grigorov M, Lawn SD, Affolter M, Griffin GE, Ferrara P, Schiffrin EJ, Morgan BP, Labeta MO: Soluble forms of Toll-like receptor (TLR)2 capable of modulating TLR2 signaling are present in human plasma and breast milk. J Immunol 2003, 171:6680-6689.

5. Iwami Kl, Matsuguchi T, Masuda A, Kikuchi T, Musikacharoen T, Yoshikai Y Cutting edge: naturally occurring soluble form of mouse Toll-like receptor 4 inhibits lipopolysaccharide signaling. J Immunol 2000, 165:6682-6686.

6. Dulay AT, Buhimschi CS, Zhao G, Oliver EA, Mbele A, Jing S, Buhimschi IA: Soluble TLR2 is present in human amniotic fluid and modulates the intraamniotic inflammatory response to infection. J Immunol 2009, 182:7244-7253.

7. Kuroishi T, Tanaka Y, Sakai A, Sugawara Y, Komine K, Sugawara S: Human parotid saliva contains soluble toll-like receptor (TLR) 2 and modulates TLR2-mediated interleukin-8 production by monocytic cells. Mol Immunol 2007, 44:1969-1976.

8. Yang HB, Xie KQ, Deng JM, Qin SM: Expression of soluble Toll-like receptors in pleural effusions. Chin Med J (Engl) 2010, 123:2225-2230.

9. Kacerovsky M, Andrys C, Drahosova M, Musilova I, Hornychova H, Lesko D, Tosner J, Jacobsson B: Soluble Toll-like receptor 1 family members in the amniotic fluid of women with preterm prelabor rupture of the membranes. J Matern Fetal Neonatal Med 2012, 25:1699-1704.

10. Kacerovsky M, Andrys C, Hornychova H, Pliskova L, Lancz K, Musilova I, Drahosova M, Bolehovska R, Tambor V, Jacobsson B: Amniotic fluid soluble Toll-like receptor 4 in pregnancies complicated by preterm prelabor rupture of the membranes. J Matern Fetal Neonatal Med 2012, 25:1148-1155.

11. Ubenauf KM, Krueger M, Henneke P, Berner R: Lipopolysaccharide binding protein is a potential marker for invasive bacterial infections in children. Pediatr Infect Dis J 2007, 26:159-162.

12. Chalupa P, Beran O, Herwald H, Kasprikova N, Holub M: Evaluation of potential biomarkers for the discrimination of bacterial and viral infections. Infection 2011, 39:411-417.

13. Andrys C, Kacerovsky M, Drahosova M, Musilova I, Pliskova L, Hornychova H, Prochazka M, Jacobsson B: Amniotic fluid soluble Toll-like receptor 2 in pregnancies complicated by preterm prelabor rupture of membranes. J Matern Fetal Neonatal Med 2013, 26:520-527.

14. Kox M, de Kleijn S, Pompe JC, Ramakers BP, Netea MG, van der Hoeven JG, Hoedemaekers CW, Pickkers P: Differential ex vivo and in vivo endotoxin tolerance kinetics following human endotoxemia. Crit Care Med 2011, 39:1866-1870.

15. ten Oever J, Riza A, Sabou M, Cismaru C, Netea MG, Slavcovici A: Characterization of the acute inflammatory response in measles infection. J Ped Infect Dis 2014, 3:197-200.

16. van de Veerdonk FL, Wever PC, Hermans MH, Fijnheer $R$, Joosten LA, van der Meer JW, Netea MG, Schneeberger PM: IL-18 serum concentration is markedly elevated in acute EBV infection and can serve as a marker for disease severity. J Infect Dis 2012, 206:197-201.

17. Giamarellos-Bourboulis EJ, Tsangaris I, Kanni T, Mouktaroudi M, Pantelidou I, Adamis G, Atmatzidis S, Chrisofos M, Evangelopoulou V, Frantzeskaki F,

Giannopoulos P, Giannikopoulos G, Gialvalis D, Gourgoulis GM, Kotzampassi K, Katsifa K, Kofinas G, Kontopidou F, Koratzanis G, Koulouras V, Koutsikou A, Koupetori M, Kritselis I, Leonidou L, Mega A, Mylona V, Nikolaou H, Orfanos S, Panagopoulos $P$, Paramythiotou $E$, et al: Procalcitonin as an early indicator of outcome in sepsis: a prospective observational study. $J$ Hosp Infect 2011, 77:58-63.

18. Levy MM, Fink MP, Marshall JC, Abraham E, Angus D, Cook D, Cohen J, Opal SM, Vincent JL, Ramsay G, Sccm/Esicm/Accp/Ats/Sis: 2001 SCCM/ESICM/ ACCP/ATS/SIS International Sepsis Definitions Conference. Crit Care Med 2003, 31:1250-1256.

19. Johnson MD, Plantinga TS, van de Vosse E, Velez Edwards DR, Smith PB, Alexander BD, Yang JC, Kremer D, Laird GM, Oosting M, Joosten LA, van der Meer JW, van Dissel JT, Walsh TJ, Perfect JR, Kullberg BJ, Scott WK, Netea MG: Cytokine gene polymorphisms and the outcome of invasive candidiasis: a prospective cohort study. Clin Infect Dis 2012, 54:502-510.

20. Mylona V, Koussoulas V, Tzivras D, Makrygiannis E, Georgopoulou P, Koratzanis G, Giamarellos-Bourboulis EJ, Tzivras MD: Changes in adaptive and innate immunity in patients with acute pancreatitis and systemic inflammatory response syndrome. Pancreatology 2011, 11:475-481.

21. Prevoo ML, van't Hof MA, Kuper HH, van Leeuwen MA, van de Putte LB, van Riel PL: Modified disease activity scores that include twenty-eight-joint counts: Development and validation in a prospective longitudinal study of patients with rheumatoid arthritis. Arthritis Rheum 1995, 38:44-48.

22. DeLong ER, DeLong DM, Clarke-Pearson DL: Comparing the areas under two or more correlated receiver operating characteristic curves: a nonparametric approach. Biometrics 1988, 44:837-845.

23. Zunt SL, Burton LV, Goldblatt LI, Dobbins EE, Srinivasan M: Soluble forms of Toll-like receptor 4 are present in human saliva and modulate tumour necrosis factor-alpha secretion by macrophage-like cells. Clin Exp Immunol 2009, 156:285-293.

24. Raby AC, Le Bouder E, Colmont C, Davies J, Richards P, Coles B, George CH, Jones SA, Brennan P, Topley N, Labeta MO: Soluble TLR2 reduces inflammation without compromising bacterial clearance by disrupting TLR2 triggering. J Immunol 2009, 183:506-517

25. Hyakushima N, Mitsuzawa H, Nishitani C, Sano H, Kuronuma K, Konishi M, Himi T, Miyake K, Kuroki Y: Interaction of soluble form of recombinant extracellular TLR4 domain with MD-2 enables lipopolysaccharide binding and attenuates TLR4-mediated signaling. J Immunol 2004, 173:6949-6954.

26. Tye H, Kennedy CL, Najdovska M, McLeod L, McCormack W, Hughes N, Dev A, Sievert W, Ooi CH, Ishikawa TO, Oshima H, Bhathal PS, Parker AE, Oshima $M$, Tan $P$, Jenkins BJ: STAT3-driven upregulation of TLR2 promotes gastric tumorigenesis independent of tumor inflammation. Cancer Cell 2012, 22:466-478

27. Marsik C, Mayr F, Cardona F, Derhaschnig U, Wagner OF, Jilma B: Endotoxaemia modulates Toll-like receptors on leucocytes in humans. $\mathrm{Br}$ J Haematol 2003, 121:653-656.

28. Cognasse F, Hamzeh H, Chavarin P, Acquart S, Genin C, Garraud O: Evidence of Toll-like receptor molecules on human platelets. Immuno Cell Biol 2005, 83:196-198.

29. Hayashi F, Means TK, Luster AD: Toll-like receptors stimulate human neutrophil function. Blood 2003, 102:2660-2669.

30. McGettrick AF, O'Neill LA: Localisation and trafficking of Toll-like receptors: an important mode of regulation. Curr Opin Immunol 2010, 22:20-27.

31. Gazi U, Rosas M, Singh S, Heinsbroek S, Haq I, Johnson S, Brown GD, Williams DL, Taylor PR, Martinez-Pomares L: Fungal recognition enhances mannose receptor shedding through dectin-1 engagement. J Biol Chem 2011, 286:7822-7829.

doi:10.1186/s12865-014-0055-y

Cite this article as: ten Oever et al:: The discriminative capacity of soluble Toll-like receptor (sTLR)2 and sTLR4 in inflammatory diseases. BMC Immunology 2014 15:55. 